\title{
Protagonismo de los alumnos en el aprendizaje. Una experiencia en el primer curso de medicina
}

\author{
Agustín Hidalgo, Javier Bordallo, Manuel Sánchez, Begoña Cantabrana
}

Objetivo. Presentar y analizar la experiencia realizada en una asignatura del primer curso del Grado de Medicina para abordar competencias formativas en documentación, método científico y humanismo médico.

Sujetos y métodos. Participaron 151 alumnos distribuidos en grupos de 5-6 estudiantes para realizar los trabajos propuestos en forma de seminarios y aprendizaje basado en problemas (ABP), utilizando, entre otros materiales, narraciones literarias e imágenes de cuadros pictóricos cuyo análisis y discusión se presentaron oralmente. En las prácticas se inició a los estudiantes en la búsqueda y evaluación de la información. Un ensayo y las clases teóricas completan los métodos utilizados. Todos los materiales a utilizar estuvieron disponibles en el campus virtual.

Resultados. La asistencia a prácticas, seminarios y ABP fue próxima al 100\%, y a clases teóricas, del 67\%. Los alumnos mostraron inquietud intelectual en las tareas. El método ha demostrado una elevada implicación en el proceso de autoaprendizaje, capacidad de autorregulación en el trabajo, trabajo en grupo, grado de adquisición de conceptos y capacidad de redactar documentos. La adecuación de los contenidos a los objetivos ha sido considerada favorable por más del $70 \%$ de los alumnos. El grado de adquisición de las competencias fue favorable en un $80 \%$ de los casos.

Conclusiones. Las características de la asignatura pueden fomentar la inquietud científica y el humanismo médico entre los alumnos. La literatura y la lectura de cuadros pueden contribuir a identificar los aspectos del acto médico y a desarroIlar la observación de las características físicas y conductuales en los pacientes.

Palabras clave. Aprendizaje basado en problemas. Autoaprendizaje. Espacio Europeo de Educación Superior. Literatura y medicina. Pintura y medicina.

Role of students in learning. An experience in the first year of Medicine Degree

Aim. To present and analyze the experience carried out in a subject of the first year of Medicine Degree to address training skills in documentation, scientific method and medical humanism.

Subjects and methods. The participants were 151 students distributed in groups of 5-6 to perform the proposed assignments in form of seminars and problem based learning (PBL), using, among other materials, short literary texts and images of paintings whose analysis and discussion were presented orally. Practical lessons introduced the students to the search and evaluation of information. An essay and lectures complete the methods used. All materials used were available in the virtual campus.

Results. Attendance at workshops, seminars and PBL sessions was close to $100 \%$ and $67 \%$ for lecture sessions. The students expressed intellectual interest on the tasks performed. The method showed high student involvement in the process of self-learning, ability of self-regulation at work, degree of concept acquisition and ability to draw up documents. The adequacy of the contents to the objectives has been considered suitable by more than $70 \%$ of the students. The acquisition of competences was favorable in $80 \%$ of cases.

Conclusions. The characteristics of the subject might be useful to promote scientific inquiry and medical humanism among students. Literature and description of paintings might help to identify aspects of medical act, as well as to develop the observation of physical and behavioral characteristics in patients.

Key words. European Higher Education Area. Literature and medicine. Painting and medicine. Problem based learning. Self-learning.

Departamento de Medicina. Facultad de Medicina. Universidad de Oviedo. Oviedo, Asturias, España.

Correspondencia: Dra. Begoña Cantabrana. Farmacología, Departamento de Medicina. Facultad de Medicina. Universidad de Oviedo. Julián Clavería, 6. E-33006 Oviedo (Asturias).

Fax:

+34985103551.

E-mail:

bego@uniovi.es

Conflicto de intereses: No declarado.

Conflict of interests: None declared.

(C) 2012 Educación Médica 


\section{Introducción}

La puesta en funcionamiento de los grados universitarios regulados por el Real Decreto 1393/2007 [1], para su adaptación al Espacio Europeo de Educación Superior, ha supuesto una oportunidad de renovación de los planes de estudios en la universidad española y el recurso a estrategias formativas no contempladas en la normativa de 1990. Algunas de las técnicas y métodos formativos que ahora se incorporan se han ensayado en diferentes universidades, en grupos de alumnos más o menos amplios, para establecer su bondad y pertinencia [2-6], y se han incorporado a los programas de formación de profesorado universitario que vive un período de interés renovado en los últimos años $[7,8]$. Uno de los objetivos -quizá el fundamental- de tales ensayos y experiencias formativas es pasar de una docencia centrada en la enseñanza a una docencia centrada en el autoaprendizaje por los alumnos [9, 10], siguiendo la recomendación del proyecto $\mathrm{Tu}$ ning [11]: 'desde las universidades se debe proponer una oferta innovadora de enfoques de enseñanza y aprendizaje para estimular, o permitir que se desarrollen, cualidades tan significativas como la capacidad de análisis y síntesis, la independencia de criterio, la curiosidad, el trabajo en equipo y la habilidad para comunicar independientemente'.

Algunas novedades que establece el aludido Real Decreto y las órdenes que recogen las competencias generales y específicas de los diferentes grados tienen que ver, entre otras, con la transversalidad, la investigación, la ética, el trabajo de fin de grado y el aumento de la práctica clínica en ciencias de la salud, sin renunciar a la formación de ciudadanos recogida en las declaraciones formativas de la universidad española desde hace muchas décadas y ejemplificada en la Misión de la universidad que Ortega y Gasset elaboró en 1930. Por otra parte, si bien desaparece la libre elección, que en la Licenciatura de Medicina ocupaba 90 créditos, se mantiene la optatividad, lo que permite plantearse formación complementaria específica de los grados y pueden proponerse itinerarios de profundización con alguna orientación dentro del grado.

En la Universidad de Oviedo se han introducido asignaturas de cierta singularidad en la articulación de las competencias atribuidas al Grado de Medicina. En concreto, se ha articulado una asignatura de documentación y metodología, tres relacionadas con investigación científica y otras dos con aspectos humanísticos abordados mediante textos literarios, películas de cine o noticias de prensa sobre aspectos sociales.
Presentamos en este trabajo la experiencia realizada en la asignatura 'Introducción a la medicina, documentación y método científico', concebida para abordar diversas competencias formativas relacionadas con la documentación, el método científico y la aproximación al humanismo médico.

\section{Sujetos y métodos \\ Organización y seguimiento de la asignatura}

Se trata de una asignatura de seis créditos ECTS con 60 horas presenciales (58 de actividades y 2 de examen escrito) y 90 horas no presenciales, que se imparte en el primer semestre del primer curso del Grado de Medicina.

Las actividades realizadas fueron las contenidas en la memoria de verificación y se resumen en la tabla I.

\section{Grupos de alumnos}

Se formaron grupos estables de cinco o seis alumnos que se mantuvieron durante el tiempo que se impartió la asignatura (un semestre). Los alumnos que se incorporaron una vez iniciado el curso fueron asignados al grupo que les correspondería por orden alfabético, por lo que excepcionalmente algunos grupos tuvieron más de seis alumnos. De esta forma se dispuso de 24 grupos, cada uno de los cuales realizó todas las tareas programadas.

Los seminarios se realizaron con grupos de $36-$ 40 alumnos (seis de los grupos descritos anteriormente), mientras que las tareas de aprendizaje basado en problemas (ABP), las tutorías grupales y las prácticas se programaron en grupos de 10-15 alumnos. Ningún alumno podía realizar más de una exposición/presentación oral, por lo que prácticamente todos debieron efectuar una.

Asimismo, los alumnos realizaron de forma obligatoria un ensayo sobre un tema relacionado con el programa de la asignatura. Por último, se recurrió a un portafolio grupal y a otro individual para que los alumnos incorporaran las descripciones de algunas de las tareas efectuadas, seleccionadas con antelación, así como el ensayo.

Con el fin de conseguir que trabajaran en colaboración, las calificaciones de las actividades de seminarios y ABP fueron las mismas para todos los integrantes de un grupo. En cambio, las calificaciones de las prácticas, del ensayo y del examen escrito fueron individuales, de tal forma que fuera posible obtener diferentes calificaciones finales entre los miembros de cada grupo. 
Tabla I. Actividades realizadas.

\begin{tabular}{|c|c|c|c|}
\hline & Horas & Concepto/definición & Actividad de los alumnos \\
\hline Clase expositiva & 20 & $\begin{array}{l}\text { Explicación por el profesor de los conceptos que } \\
\text { configuran el cuerpo doctrinal de la asignatura }\end{array}$ & Asistencia voluntaria a clase ${ }^{a}$ \\
\hline Clases prácticas & 10 & $\begin{array}{l}\text { Realización de tareas de documentación, } \\
\text { comprensión del campus virtual e incorporación } \\
\text { de tareas al portafolio, bajo la supervisión del } \\
\text { profesor }\end{array}$ & $\begin{array}{l}\text { Manejo del campus virtual } \\
\text { Fuentes secundarias de documentación } \\
\text { Búsqueda de documentación I } \\
\text { Búsqueda de documentación II } \\
\text { Búsqueda de documentación III y ejercicios de } \\
\text { incorporación de materiales al campus virtual }\end{array}$ \\
\hline Seminarios & 15 & $\begin{array}{l}\text { Sesiones de presentación y discusión } \\
\text { de trabajos por los alumnos } \\
\text { En una sesión de una hora, el profesor instruye en } \\
\text { la dinámica mediante la presentación de un caso }\end{array}$ & $\begin{array}{l}\text { Análisis de descubrimientos científicos } \\
\text { Demanda de asistencia médica } \\
\text { Mirar y describir un cuadro (dos sesiones) } \\
\text { Análisis de textos literarios (dos sesiones) } \\
\text { Análisis de trabajos científicos }\end{array}$ \\
\hline $\begin{array}{l}\text { Aprendizaje basado } \\
\text { en problemas }\end{array}$ & 7 & $\begin{array}{l}\text { Los alumnos deben abordar tareas que obliguen } \\
\text { a la utilización de metodología científica, } \\
\text { descripción de enfermedades y razonamiento } \\
\text { clínico, así como hacer una presentación oral }\end{array}$ & $\begin{array}{l}\text { Describir una enfermedad } \\
\text { Identificar términos científicos y médicos en la prensa } \\
\text { Publicidad y salud } \\
\text { Análisis de descubrimientos científicos } \\
\text { Análisis de publicaciones científicas }\end{array}$ \\
\hline Ensayo & $\begin{array}{c}\text { No } \\
\text { presencial }\end{array}$ & $\begin{array}{l}\text { Escrito en el cual un autor desarrolla sus ideas, } \\
\text { utilizando un lenguaje adecuado para que pueda } \\
\text { entenderlo el destinatario }\end{array}$ & $\begin{array}{l}\text { Redacción de un ensayo original sobre metodología } \\
\text { de la ciencia, aspectos sociales de la ciencia o la } \\
\text { profesión médica }\end{array}$ \\
\hline Tutoría grupal & 6 & \multicolumn{2}{|c|}{$\begin{array}{l}\text { Sesiones de discusión no programada, centradas en la orientación para la preparación de las exposiciones } \\
\text { y trabajos de los alumnos y, en menor medida, en la resolución de dudas generales de la marcha del curso }\end{array}$} \\
\hline Evaluación & 2 & \multicolumn{2}{|c|}{$\begin{array}{l}\text { Examen escrito tipo pregunta corta sobre contenidos presentados y comentados en todas las actividades, } \\
\text { pero preferentemente en las clases expositivas, dado que prácticas, seminarios y tareas de aprendizaje } \\
\text { basado en problemas tenían calificaciones propias }\end{array}$} \\
\hline
\end{tabular}

a El estatuto de la Universidad de Oviedo establece que la asistencia a las clases teóricas no es obligatoria.

\section{Programación de la asignatura}

La distribución horaria de la asignatura quedó establecida en mayo del año 2010, cuando la Junta de Facultad aprobó el plan docente para el curso académico 2010-2011. Por tanto, con antelación suficiente conocíamos el número y la distribución de las horas disponibles para cada una de las actividades del curso. A partir de este momento, y hasta la recepción de las listas de matrícula, elaboramos una tentativa programación interna de la asignatura, que fue definitiva en el momento de comenzar. Se programaron las tareas a realizar en las distintas actividades y se elaboraron los siguientes documentos:

- Asignación de tareas a cada una de las actividades. Cada grupo tenía asignadas sus narraciones y cuadros para el posterior análisis. Además, cada grupo debía elegir un descubrimiento científico y una enfermedad para trabajar en las tareas de ABP.
- Diseño de una actividad introductoria a los seminarios y ABP. El profesor realiza, de forma demostrativa, una tarea para que los alumnos conozcan la dinámica de trabajo que se propone y los objetivos que se pretenden. En algunos seminarios también hubo una breve (máximo de 15 minutos) presentación por el profesor de algunos conceptos y objetivos concretos de ciertas tareas. Con este fin, se comentaron los poema $E l$ desahuciado, de Gabriel y Galán [12], y Llega el litio, de Goytisolo [13], así como una breve narración referida a la actuación de un médico rural contenida en Un hombre afortunado, de John Berger [14]. Los materiales orientativos aportados para seminarios y ABP se han extraído de obras generales publicadas [15-22].

- Selección de textos narrativos y de cuadros para su análisis y discusión en seminarios y en $A B P$. Se utilizaron un total de 24 narraciones de $\mathrm{M}$. Be- 
Tabla II. Grado de satisfacción de los estudiantes con los métodos utilizados en la asignatura

\begin{tabular}{lcccccc}
\hline & Muy poco & Poco & Regular & Bastante & Mucho & ns/nc \\
\hline Organización general & $2,1 \%$ & $19,3 \%$ & $35,7 \%$ & $32,9 \%$ & $6,4 \%$ & $3,6 \%$ \\
\hline ABP & $1,4 \%$ & $10 \%$ & $31,4 \%$ & $38,6 \%$ & $17,1 \%$ & $1,4 \%$ \\
\hline Seminarios & $0,7 \%$ & $7,9 \%$ & $27,1 \%$ & $42,1 \%$ & $20,0 \%$ & $2,1 \%$ \\
\hline Evaluación & $0,7 \%$ & $5,0 \%$ & $15,0 \%$ & $52,1 \%$ & $25,7 \%$ & $1,4 \%$ \\
\hline
\end{tabular}

ABP: aprendizaje basado en problemas; ns/nc: no sabe/no contesta

nedetti, A. Caravaca Caballero, W. Carlos Williams, A. Chejov, A. Conan Doyle, J. Fernández Guerra, S. Hernández, F. Kafka y A. Pereira. Cada grupo debía analizar y comentar dos narraciones en su grupo de seminarios. De igual forma, debieron comentar dos cuadros, lo que supuso la selección de 50, pertenecientes a diferentes épocas y estilos pictóricos.

- Diseño de los protocolos para las prácticas con las indicaciones necesarias para la utilización del campus virtual y de la búsqueda de información en distintas bases documentales. En ellos se especifican las palabras clave y los límites de búsqueda que deben utilizar, así como las indicaciones para elaborar un documento con los resultados obtenidos para incorporar al campus virtual.

- Instrucciones para la elaboración de un ensayo. Se propusieron una serie de temas relacionados con 'ciencia y sociedad', 'ciencia y medicina' e 'historia de la medicina', pero se permitió que el alumno pudiera elegir otro no incluido en la propuesta. También se indicó una bibliografía orientativa para los temas propuestos.

Al comienzo de la asignatura los alumnos disponían, en el campus virtual de la Universidad de Oviedo, de:

- Programa de la asignatura con criterios de evaluación y bibliografía orientativa, así como relación de competencias y resultados de aprendizaje esperados.

- Cronograma del curso.

- Guiones para la elaboración de las prácticas.

- Guiones/explicaciones breves sobre los objetivos y abordajes de seminarios, ABP y ensayos.

- Bibliografía relacionada con las tareas a realizar.

- Textos de los trabajos de investigación y de las narraciones a analizar.

- Imágenes de los cuadros que debían comentar.

- Diapositivas de las clases expositivas.
Figura 1. Valoración obtenida en algunos ítems seleccionados.

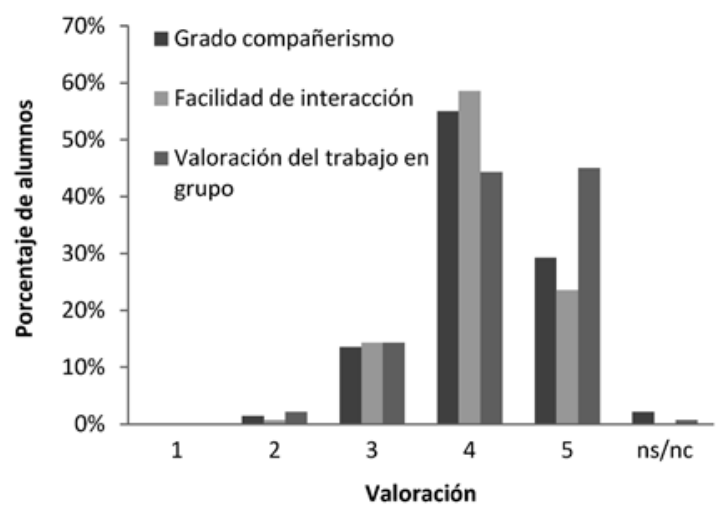

- Colección de preguntas para ejercitar los conocimientos de cada uno de los temas impartidos en las clases expositivas.

\section{Evaluación del aprendizaje}

Se realizaron diferentes tipos de evaluación, cada uno de las cuales contribuyó a la calificación final. Así, el examen escrito, una prueba de preguntas cortas, significó hasta el 50\% de la calificación final. Las tareas de prácticas correctamente realizadas y entregadas en el campus virtual aportaron hasta el $20 \%$; las presentaciones orales de seminarios y ABP expuestas en el aula, hasta el 15\%, y las actividades incorporadas al portafolio (tareas escritas de seminarios, ABP y ensayo), hasta otro $15 \%$.

\section{Encuesta}

Con el fin de poder cuantificar la opinión de los alumnos sobre aspectos de la asignatura relacionados con el aprendizaje, los métodos, el trabajo en grupo y la adquisición de competencias, diseñamos una encuesta de satisfacción. Los alumnos la cumplimentaron, de forma voluntaria y anónima, al final del examen escrito.

\section{Resultados y discusión}

El número de alumnos matriculados en el curso 2010-2011 fue de 154; de ellos, 140 de primera matrícula y 14 adaptados. Accedieron desde la prueba de acceso a la universidad 132 alumnos; desde otra titulación, cuatro; por mayores de 25 años, tres, y 
por mayores de 45 años, uno. Llegaron a final del semestre 151 alumnos, ya que tres abandonaron. La nota de corte de acceso en los alumnos de la prueba de acceso a la universidad fue de 12,579.

Al examen se presentaron 146 alumnos, de los cuales suspendió uno. Al evaluar el conjunto de actividades obtuvieron la calificación de aprobado nueve alumnos; notable, 115; sobresaliente, 14, y matrícula de honor, siete.

La encuesta de satisfacción aplicada a los alumnos fue contestada por 140 (92,7\%) del total de 151 que terminaron el curso. La valoración se trasladó a una escala numérica considerando el grado de acuerdo con los siguientes términos: 1 , muy poco; 2 , poco; 3 , regular; 4 , bastante; 5 , mucho; ns/nc, no sabe/no contesta. Los resultados obtenidos se muestran en las figuras y las tablas; no obstante, destacamos algunos de ellos.

La única actividad presencial en la que no se realizó control de asistencia fue la clase teórica. El 67\% de los alumnos encuestados afirmó asistir a clase teórica. Siendo ésta una actividad voluntaria, el elevado porcentaje de alumnos que asistió regularmente a clase estaba en consonancia con el perfil de ingreso de los estudiantes de medicina, con elevadas calificaciones y preferentemente vocacionales $[23,24]$. Este mismo carácter y la edad pueden justificar el alto grado de compañerismo y de interacción entre los alumnos, además del interés en las tareas propuestas (Fig. 1).

En la encuesta también destaca que la peor puntuación fue para la organización general (Tabla II). Pensamos que esto, en parte, se debe a que ha sido el primer año que se pone en marcha el grado y algunos aspectos de la organización general del curso no estaban institucionalmente resueltos por completo. Así, por ejemplo, en ocasiones las aulas asignadas para los seminarios no eran las correctas, los alumnos que se incorporaron más tarde no tenían las claves para acceder al campus virtual, en la sala de informática asignada a prácticas la disponibilidad de ordenadores era subóptima o los desplazamientos de una clase a otra eran demasiado largos. Esto provocaba cierta sensación de desorganización. A pesar de ello, sólo un $20 \%$ de los alumnos encuestados se consideraba poco satisfecho. Como puede observarse en la tabla II, más del $70 \%$ consideraba que el ABP, el planteamiento de los seminarios y las clases teóricas eran buenos. Este porcentaje alcanza el 60\% en el caso de los seminarios. Por otra parte, el proceso de evaluación se consideraba en más del $75 \%$ como bueno o muy bueno (Tabla II).

Es importante señalar el entusiasmo de los alumnos en la descripción de las enfermedades, que pre-
Tabla III. Opinión de los estudiantes sobre el grado de adecuación de los contenidos a los objetivos de la asignatura.

\begin{tabular}{lcccccc}
\hline & Muy poco & Poco & Regular & Bastante & Mucho & ns/nc \\
\hline Clases teóricas & $1,4 \%$ & $8,6 \%$ & $24,3 \%$ & $52,1 \%$ & $10,0 \%$ & $3,6 \%$ \\
\hline ABP & $0,7 \%$ & $2,1 \%$ & $18,6 \%$ & $57,1 \%$ & $17,9 \%$ & $3,6 \%$ \\
\hline Seminarios & $0,7 \%$ & $5,0 \%$ & $17,9 \%$ & $56,4 \%$ & $19,3 \%$ & $0,7 \%$ \\
\hline Ensayo & $1,4 \%$ & $9,3 \%$ & $23,6 \%$ & $40,0 \%$ & $21,4 \%$ & $4,3 \%$ \\
\hline
\end{tabular}

ABP: aprendizaje basado en problemas; ns/nc: no sabe/no contesta.

Figura 2. Aprendizaje del alumno.

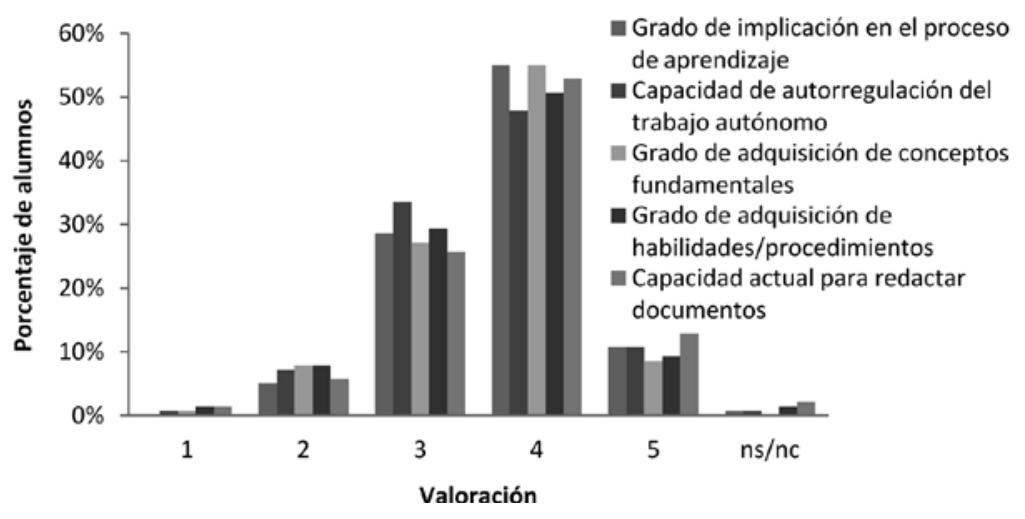

Figura 3. Valoración de aspectos generales de la asignatura.

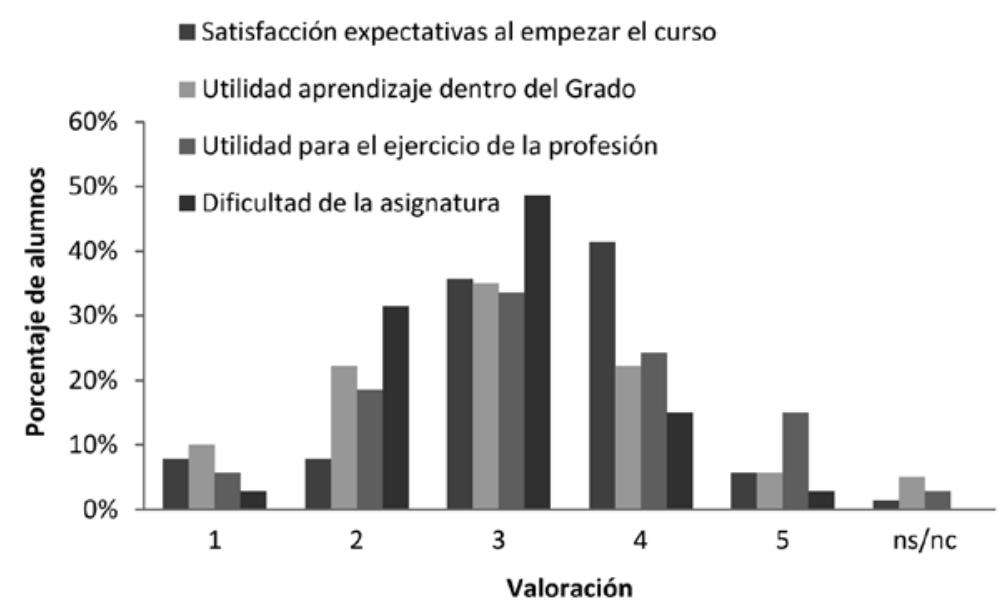


Tabla IV. Grado de adquisición de las competencias.

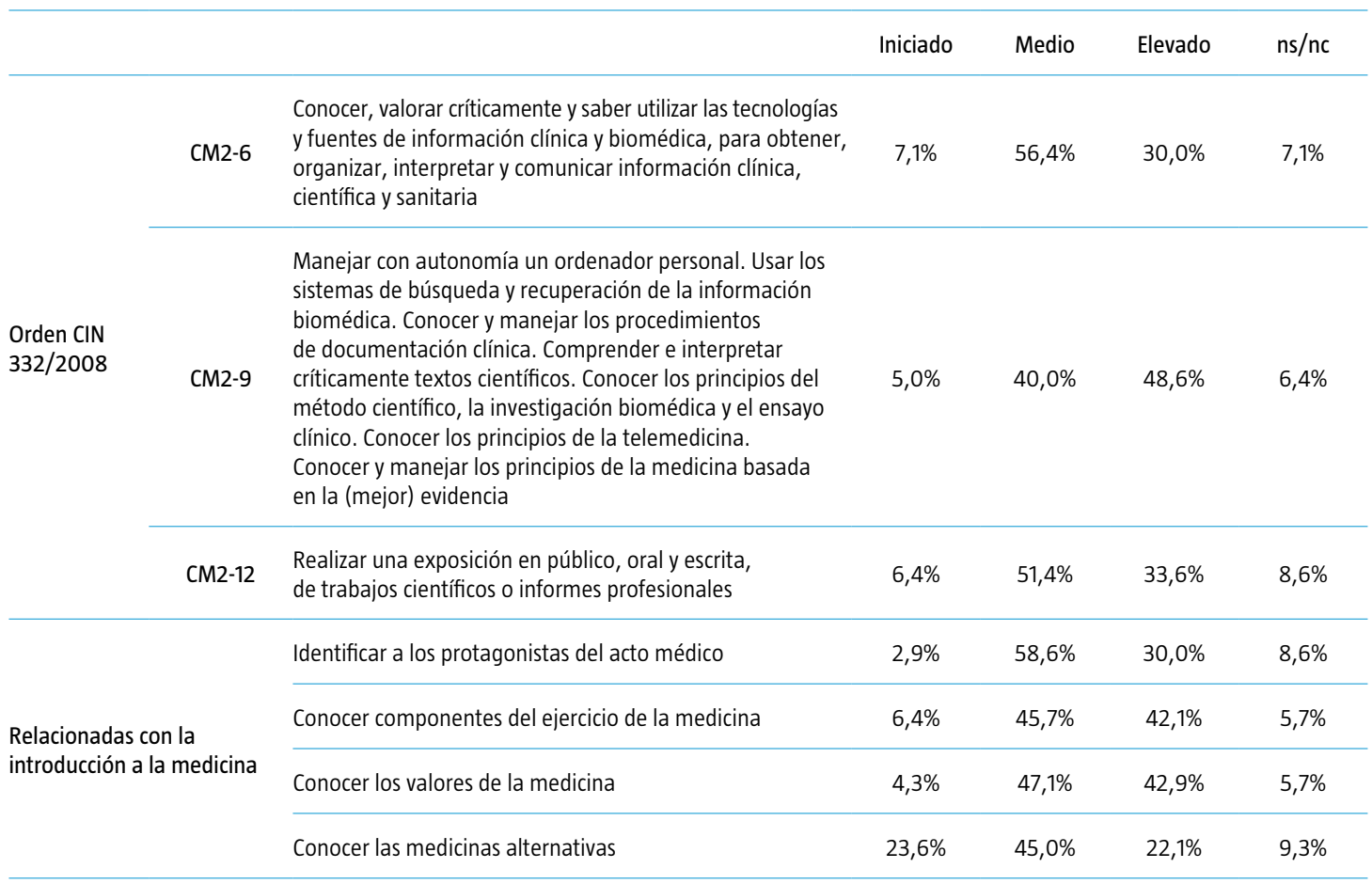

ns/nc: no sabe/no contesta.

sentaban con profusión de datos y pruebas complementarias. El único aspecto a corregir, según nuestro criterio, fue la elección de las enfermedades, mas próximas a entidades llamativas que a patologías frecuentes; por eso consideramos que una inmersión precoz en la clínica puede ser beneficiosa en la formación de los estudiantes [25]. Por otra parte, las sesiones dedicadas a descubrimientos científicos y a comentarios de trabajos de investigación tuvieron la atención de los alumnos, que mostraron disposición y cualidades adecuadas para su desarrollo, e inquietud intelectual. Esta circunstancia anima a incidir en la formación en investigación de los estudiantes de medicina desde los primeros cursos, con el fin de incrementar la dedicación de graduados en Medicina a tareas docentes y de investigación [26]. La adecuación de los materiales utilizados queda corroborada por los datos de la tabla III, que muestra que más del $60 \%$ de los alumnos encuestados consideraba que eran bastante o muy adecuados.

El valor formativo del cine y la literatura ha sido resaltado por varios autores [27-29]. Nuestra experiencia en este curso apunta en el mismo sentido, tanto en la aceptación por los alumnos como en el potencial formativo de la literatura en dos aspectos fundamentales de la práctica médica: la descripción (del aspecto y signos del paciente y de la narración de la enfermedad) y la identificación/aproximación al enfermo como doliente y sujeto de la atención sanitaria. El poder formativo de la literatura puede contribuir al ideal médico de Oliver Sacks, quien escribió que, para situar de nuevo en el centro al sujeto (el ser humano que se aflige y que lucha y padece), hemos de profundizar en un historial clínico hasta hacerlo narración o cuento.

Por último, hemos intentado que los alumnos empiecen a concienciarse del papel de la observación en la medicina. Para ello hemos recurrido, de forma gratificante, a una experiencia de la Universidad de Yale [30] en la que los alumnos leen cuadros en un museo. En nuestra experiencia hemos utilizado fotografías de cuadros. La experiencia sugiere que, dada la gran capacidad de observación y descripción detallada de las imágenes, disponemos de alumnos con cualidades para convertirse en buenos profesionales sanitarios.

Cuando los alumnos valoraban distintos aspectos de su aprendizaje, como la implicación, el traba- 
jo autónomo, la adquisición de habilidades o la capacidad para redactar documentos, más del $50 \%$ lo calificaron como bastante o muy bueno (Fig. 2). La figura 2 también informa de que nuestro empeño se ha orientado más a la adquisición de conceptos fundamentales que a aspectos memorísticos. Además, al tener que redactar (historias clínicas, narraciones y ensayos), los métodos seguidos permiten la adquisición de competencias de documentación y expresión.

En cuanto al grado de adquisición de las competencias (Tabla IV), prácticamente hubo unanimidad en que éstas se habían conseguido con un nivel medio (aproximadamente 45\%) o elevado (30-50\%).

También el 50\% de los alumnos pensaba (Fig. 3) que la asignatura tenía su utilidad para el aprendizaje en el grado y en el ejercicio de la profesión, si bien la cuantificación de su implantación real debe tomarse con reservas porque se trata de alumnos de primer curso. Por ello, podría ser interesante una evaluación en cursos posteriores.

Bibliografía

1. Real Decreto $1393 / 2007$, de 29 de octubre, por el que se establece la ordenación de las enseñanzas universitarias oficiales. Boletín Oficial del Estado 2007; 260: 44037-48.

2. Baños JE, Pérez J. Cómo fomentar las competencias transversales en los estudios de ciencias de la salud: una propuesta de actividades. Educ Med 2005; 8: 215-24.

3. Cantabrana B, Sánchez M. Innovación docente en la asignatura Farmacología, Nutrición y Dietética del $2 .^{\circ}$ curso de la Diplomatura de Enfermería, 2006-7. II Jornadas de intercambio de experiencias en docencia universitaria en la Universidad de Oviedo. Oviedo: Ediuno; 2008.

4. Cantabrana B, Suárez S, Sánchez M. Academic results by introducing complementary teaching methods in pharmacology. Eur J Clin Pharmacol 2010; 66: S128.

5. Hidalgo A, Suárez S, Revuelta L, Díez B, Menéndez L, Cantabrana B. Press news and pharmaceutical publicity in the teaching-learning process of pharmacology. Eur J Clin Pharmacol 2010; 66: S120.

6. Valero M, Aramburu J, Baños JE, Sentí M, Pérez J. Introducción de un portafolio para fomentar competencias transversales de los estudiantes universitarios. Educ Med 2007; 10: 244-51.

7. Rodríguez R, Hernández J, coords. Proyectos de innovación docente. Oviedo: Instituto de Ciencias de la Educación de la Universidad de Oviedo; 2006.

8. Universidad de Oviedo. II Jornadas de intercambio de experiencias en docencia universitaria en la Universidad de Oviedo. Oviedo: Ediuno; 2008.

9. Sosa-Moreno F. De la docencia centrada en la enseñanza a la docencia centrada en el aprendizaje: principios y estrategias para una metodología innovadora en la educación superior. In Reyes-García CI, coord. El espacio europeo de educación superior: algunas cuestiones clave. Las Palmas: Universidad de Las Palmas de Gran Canaria; 2007. p. 131-66.

10. Del Moral ME, Rodríguez R, coords. Experiencias docentes y tic. Barcelona: Octaedro; 2008.

11. González J, Wagenaar R. Tuning educational structures in Europe. Bilbao: Universidad de Deusto; 2003.

12. Gabriel y Galán JM. El desahuciado. In Gabriel y Galán JM. Obras completas. Badajoz: Universitas Editorial; 1996. p. 175-8.

13. Goytisolo JA. Llega el litio. In Goytisolo JA. De las horas quemadas. Barcelona: Lumen; 1996.

14. Berger J. Un hombre afortunado. Madrid: Alfaguara; 2008.

15. Alinovi M. Historia de las epidemias. Pestes y enfermedades que aterrorizaron (y aterrorizan) al mundo. Buenos Aires: Capital Intelectual; 2009.

16. Aris A. Medicina en la pintura. Madrid: Lundwerg; 2010

17. Carranza FA. Héroes de la medicina. Bs. Aires: Eudeba; 2008.

18. Esteva J, Prieto J, Puerto J. El medicamento y la vida humana. Madrid: Ars Medica; 2005

19. Macip S. Las grandes plagas modernas. Barcelona: Destino; 2010.

20. Ordóñez J. Ideas e inventos de un milenio 900-1900. Madrid: Lundwerg; 2008.

21. Silverman M. Drogas mágicas. 3 ed. Buenos Aires: Editorial Sudamericana; 1944.

22. Vigué J, Ricketts M. La medicina en la pintura. El arte médico. Madrid: Ars Médica; 2008

23. Gutiérrez-Medina S, Cuenca-Gómez D, Álvarez de Toledo O. ¿Por qué quiero ser médico? Educ Med 2008; 11 (Supl 1): S1-6.

24. Soria M, Guerra M, Giménez I, Escanero JF. La decisión de estudiar medicina: características. Educ Med 2006; 9: 91-7.

25. Baños JE, Sentí M, Miralles R. Contacto precoz con la realidad asistencial: una experiencia piloto en medicina. Educ Med 2011; 14: 39-47.

26. Giménez JM. Necesidad de médicos dedicados a la docencia universitaria y a la investigación biomédica básica. Educ Med 1999; 2: 192-3.

27. Baños JE. El valor de la literatura en la formación de los estudiantes de medicina. Educ Med 2003; 6: 93-9.

28. Barbado-Hernández FJ. Medicina y literatura en la formación del médico residente de medicina interna. An Med Interna 2007; 24: 195-200.

29. Loscos J, Baños JE, Loscos T, De la Cámara J. Medicina, cine y literatura: una experiencia docente en la Universitat Autònoma de Barcelona. Rev Med Cine 2006; 2: 138-42.

30. Sanders L. Diagnóstico. Barcelona: Debolsillo; 2010. 